NOTE

\title{
Deposit feeding: a novel mode of nutrition in the Antarctic colonial soft coral Gersemia antarctica
}

\author{
Marc Slattery ${ }^{1,2, *}$, James B. McClintock ${ }^{2}$, Sam S. Bowser ${ }^{3,4}$ \\ 'University of Mississippi, Department of Pharmacognosy and National Center for the Development of Natural Products, Research Institute of \\ Pharmaceutical Sciences, School of Pharmacy, University, Mississippi 38677, USA \\ ${ }^{2}$ University of Alabama at Birmingham, Department of Biology, Birmingham, Alabama 35294, USA \\ ${ }^{3}$ Wadsworth Center for Laboratories and Research, New York State Department of Health, PO Box 509, Albany, New York 12201, USA \\ ${ }^{4}$ University at Albany, State University of New York, Department of Biomedical Sciences, Albany, New York 12222, USA
}

\begin{abstract}
The colomal nephtheid soft coral Gersemia antarctica is a deposit feeder in the soft sediment communities of McMlurdo Sound, Antarctica. This feeding strategy involves coordinated bending of the entire colony against the substrate and is previously undescribed among soft corals. Gut content analyses indıcate a mixed diet that includes benthic diatoms, foraminiferans, and particulate organic matter. Soft coral colonies move periodically in an 'inch worm' fashion, presumably to exploit undisturbed sediments. In fact. when colonies encounter previously grazed sediment they contract from the substrate almost immediately. This feeding strategy has likely evolved to supplement the capture of planktonic prey and is of particular importance in the Antarctic, and potentially the deep sea, where water column productivity is seasonally constrained.
\end{abstract}

KEY WORDS: Deposit feeding Soft coral - Antarctica $\cdot$ Benthic communities

Coral nutrition has been a topic of much interest to marine ecologists since both scleractinian (= hard) and alcyonacean ( $=$ soft) corals are such abundant members of tropical hard-bottom communities (Veron 1995). Two predominate forms of nutrition are observed in corals: (1) photoautotrophy via symbiotic zooxanthellae, and (2) heterotrophy. The mechanisms of photoautotrophy have been well documented (Muscatine \& Porter 1977, Muscatine et al. 1981); heterotrophic feeding appears to be a largely passive process that relies on suspended particles being carried by a current to the coral (LaBarbera 1984, Patterson 1991a, b). Alcyonacean heterotrophy has long been accepted as exclusive zooplanktivory; that is to say the soft corals are assumed to passively filter small crustaceans

•E-mail:mslatter@olemiss.edu and various invertebrate eggs and larvae from the surrounding seawater (Lewis 1982, Sorokin 1991). However, Fabricius et al. (1995) recently provided evidence that an asymbiotic soft coral, Dendronephthya hemprichi, in the Red Sea could balance its nutritional requirements almost entirely via passive filtration of phytoplankton. Nonetheless, questions persist regarding the acquisition of nutrients by soft corals particularly in nutrient poor or low flow ecosystems.

The shallow benthic soft-bottom communities of western McMurdo Sound, Antarctica (77 $34^{\prime} \mathrm{S}, 166^{\circ}$ $39^{\prime} \mathrm{E}$ ) are considered nutrient limited (Dayton et al. 1986: chl a levels are approximately an order of magnitude lower than in eastern McMurdo Sound) and characterized by low flow (Barry \& Dayton 1988, Gooday et al. 1996: flow $\& 1 \mathrm{~cm} \mathrm{~s}^{-1}$ ) (Dayton et al. 1994, $\mathrm{M}$. Slattery pers. obs.). Nonetheless, the large nephtheid soft coral Gersemia antarctica thrives in this system (Slattery \& McClintock in press); biochemical and energetic composition were similar to those of Antarctic soft corals at high nutrient sites and to tropical Pacific soft corals (Slattery \& McClintock 1995, M. Slattery unpubl. data). The abundance of soft corals in a plankton depauperate system is a paradox as Antarctic soft corals, including $G$. antarctica, apparently lack zooxanthellae (M. Slattery pers, obs.) and consequently must rely on heterotrophy for their nutritional needs. Here we report on a feeding strategy exploited by $G$. antarctica which is unique among all soft corals studied and appears to solve this paradox.

Materials and methods. Periodic observations of populations of Gersemia antarctica were conducted using SCUBA at Explorer's Cove, the Bay of Sails, and Granite Harbor in the Southern Ross Sea during Octo- 
ber-December 1989, October-January 1992-93, and August-February 1993-94. Quantitative surveys of the population at Explorer's Cove (see methods in Slattery \& McClintock 1995 and site descriptions in Dayton \& Oliver 1977, Mullineaux \& DeLaca 1984, Stockton 1984, Gooday et al. 1996) indicated the colonies were widely spaced (ca 4 per $100 \mathrm{~m}^{2}$ ), patchy, and living under conditions unsuitable for passive suspension feeding (i.e. plankton limited and low hydrodynamic flow: Dayton et al. 1986, Barry and Dayton 1988, Gooday et al. 1996); similar conditions were noted at the Bay of Sails and Granite Harbor sites (Slattery \& McClintock 1995, M. Slattery pers. obs.). Individual colonies were marked at Explorer's Cove using numbered PVC stakes hammered into the sediment approximately $10 \mathrm{~cm}$ from a given soft coral colony ( $n=27$ corals marked over the 3 field seasons). When possible a color-coded cable tie was also affixed to the 'substrate anchor' (see description below) of each soft coral colony, providing a second means of identifying individual colonies. Divers recorded colony postures and rates of colony movement during successive dives at the Explorer's Cove site and photographed individual colonies using a Nikonos V camera. During the 1993-94 field season, an underwater video system consisting of a Sony SSC-C350 CCD camera, rated at 470 lines resolution and 2.5 lux, mounted in an underwater housing (Fieldcam TLV Fuhrman Diversified, Seabrook, TX, USA), was positioned on a stainless steel tripod ( $\sim 0.3 \mathrm{~m}$ tall) near the Explorer's Cove population. The imaging signal was carried to the surface by a $46 \mathrm{~m}$ water proof coaxial cable and recorded at 1.6 images s$^{-1}$ (96 h mode) with a Sony EVT-820 $8 \mathrm{~mm}$ time-lapse videocassette recorder over a period of 1 to
2 wk. Ambient light conditions were too diffuse to produce useful images, so a $1000 \mathrm{~W}$ Berns and Sawyer underwater light was used to illuminate the subject area (distance from lamp to soft coral $\geq 3 \mathrm{~m}$ ). The voltage drop attributable to the $90 \mathrm{~m}$ of underwater electrical cable resulted in a lamp output rating of $300 \mathrm{~W}$; the actual light intensity was not determined. Comparisons of the marked populations of G. antarctica in Explorer's Cove and populations at the Bay of Sails and Granite Harbor, and those videotaped suggest the presence of the light source had little effect on feeding behavior. It is conceivable that feeding rate might have been reduced but our data would represent a conservative estimate of this activity pattern. Feeding polyps were removed from colonies during the 1989 and 1993-94 field seasons ( $\mathrm{n}=4$ colonies sampled total), fixed in formaldehyde and transferred to $70 \% \mathrm{EtOH}$, and sectioned under a Nikon dissecting scope. Gut contents were identified and grouped generally as diatoms, foraminiferans, and unidentifiable particulate organic matter.

Results and conclusions. Gersemia antarctica colonies attached to either scallop shells or small rocks and clay via their basal disc; this provided an adequate 'substrate anchor' for the fine silt $(\phi \geq 5 ;$ D. Bockus unpubl. data) and low current conditions (Barry \& Dayton 1988). The colonies were capable of significant hydrostatic expansion with colony height increasing from 35 to $275 \mathrm{~cm}$ over $\leq 6 \mathrm{~h}$ (M. Slattery pers. obs.). Nonetheless, erect colonies in the water column spent little time in this posture $(4.25 \pm 3.83 \mathrm{~min}, \bar{x} \pm \mathrm{SD}, \mathrm{n}=22$ observations of 27 soft corals; process of hydrostatic inflation through initial bending: Figs. 1 \& 2A). Instead, fully inflated colonies continued to bend (Fig. 2B) and

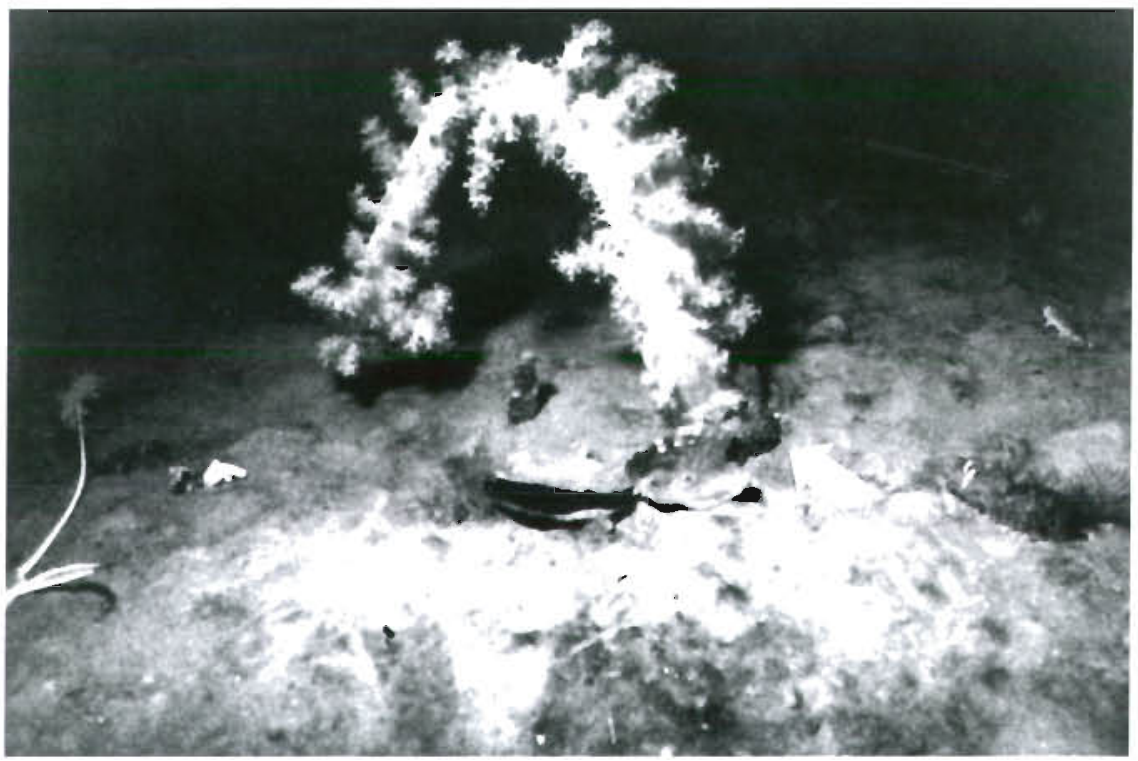

Fig. 1. Gersemia antarctica. The soft coral from an underwater photograph in Explorer's Cove, McMurdo Sound, Antarctica, November 1993. The size of this colony was approximately $2 \mathrm{~m}$ tall with the hydrostatic skeleton fully inflated. The colony has begun bending towards the substrate to initiate deposit feeding. At the base of the colony, to the right of the scallops Adamussium colbecki, note the arrow pointing at the 'sediment anchor' which is pulled slightly free of the substrate 

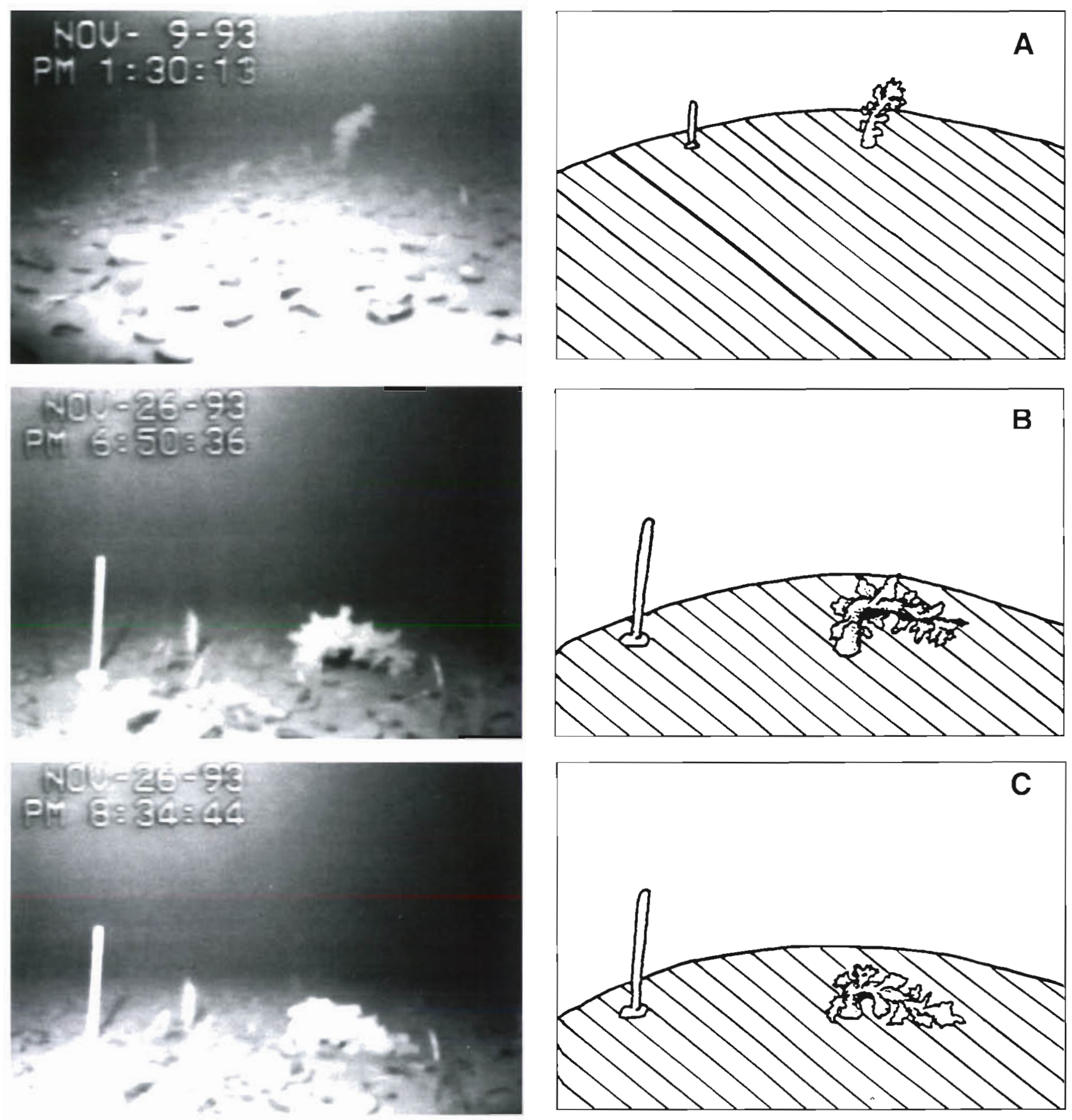

Fig. 2. Gersemia antarctica. The soft coral from a sequence of realtime video in Explorer's Cove, McMurdo Sound, Antarctica, 9 to 26 November 1993 (see text for details on the video system). A line drawing is included to clarify the position and posture of the soft coral colony. (A) This individual, in the process of colony hydrostatic skeleton inflation, was approximately $1 \mathrm{~m}$ tall; note the marker stake to the left of the individual $\approx 0.5 \mathrm{~m}$ tall. The video camera was repositioned following this sequence to increase resolution. (B) The colony begins to bend towards the substrate at 18:50:36 h. (C) The colony has contacted the substrate and begun feeding at 20:34:44 h, approximately $1.75 \mathrm{~h}$ after bending towards the substrate

then lie over onto the substrate (Fig. 2C). The polyps were then extended and were observed to pick at the sediment interface $(6.33 \pm 4.75 \mathrm{~min}, \mathrm{n}=36$ observations of 27 soft corals; initial contact with sediment in- terface through polyp extension: Fig. 3). Over variable periods of time $(3-45 \mathrm{~min}$, i.e. the duration of a dive) the outstretched colonies contracted towards their basal substrate anchor by expelling seawater from their 


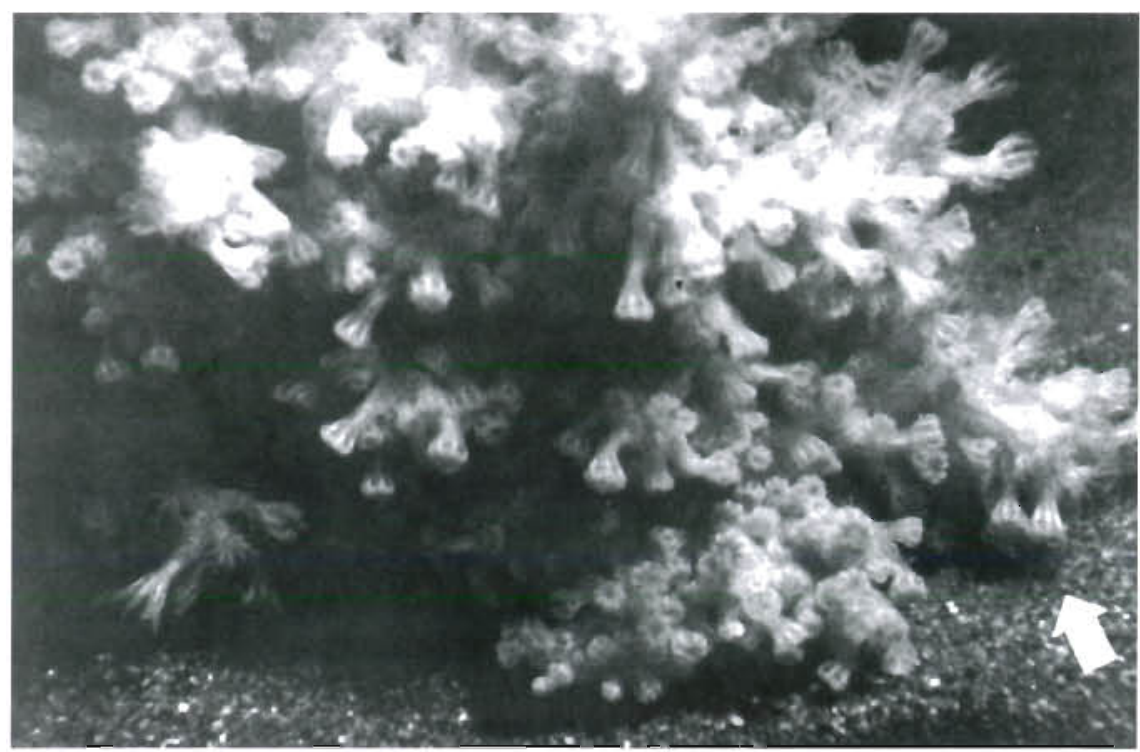

Fig. 3. Gersemia antarctica. The soft coral from a 3:1 macro UW photograph in Explorer's Cove, McMurdo Sound, Antarctica, November 1994. The size of each polyp is approximately $0.5 \mathrm{~cm}$. Note the polyps consuming particles (arrow) and picking at the sediment interface in the lower left corner of the photo

'hydrostatic skeletons' ( $\mathrm{n}=83$ independent observations of 27 soft corals). Within a $24 \mathrm{~h}$ period at Explorer's Cove, 12 soft coral colonies were each observed to inflate, bend and feed, and then contract a minimum of 5 times per colony. Upon each subsequent return to a prone posture against the sediment, the soft corals were invariably oriented in a different direction ( $n=47$ independent observations of 12 soft corals). Thus each soft coral colony was constantly 'grazing' new sediment. On 2 occasions, soft coral colonies were observed returning to previously grazed sediment, in both instances the colonies contracted within 3 min of extending the feeding polyps against the substrate. Similar feeding behaviors were noted for populations of G. antarctica at the Bay of Sails and Granite Harbor.

Over sufficient time a circular area surrounding each Gersemia antarctica colony (radius $\approx 150$ to $300 \mathrm{~cm}$ : approximate height ranges of an erect adult colony) would be expected to become depleted in prey and particulate organics. To accommodate relocation to suitable substrate, $G$. antarctica colonies were observed by divers to move via an 'inch-worm' process ( $\mathrm{n}$ $=3$ independent observations of 27 soft corals). Effectively, from an expanded prone position, the soft coral colony freed its 'substrate anchor' from the sediment through a series of contractions localized in its basal region. Once free of the substrate a colony proceeded to inflate its hydrostatic skeleton, extending its distal mass away from its site of origin. Water expulsion and contraction, initiated at the basal region of the colony, resulted in a net forward inch-worm-like movement of the entire colony in the direction of the extended terminal region. The entire locomotory sequence progressed slowly; we observed locomotion events that spanned $48 \mathrm{~h}$. However, we never directly observed a colony re-anchoring itself in the sediment. Of the 3 colonies which moved, 2 anchored themselves between our dives, while the third colony remained unanchored for at least $4 \mathrm{~d}$ and was subsequently identified 9 mo later, via coded cable ties, anchored $7 \mathrm{~m}$ from its site of origin. While unanchored this individual exhibited feeding behavior (i.e. the individual was capable of expansion and contraction and polyps were observed picking at the sediment interface). Between the 1992-93 and 1993-94 field seasons, 6 marked colonies relocated themselves $(14.2 \pm 6.5 \mathrm{~m}, \bar{x} \pm \mathrm{SD}$ distance from original site). An additional 5 colonies did not relocate in approximately $8 \mathrm{mo}$; they were located immediately adjacent to their marker stakes.

The deposit feeding behavior exhibited by Gersemia antarctica represents a novel trophic strategy for soft corals; we know of no similar observations among other soft corals. Explorer's Cove and other soft-bottom communities surrounding McMurdo Sound, Antarctica, support an abundant and diverse assemblage of marine invertebrates (Dayton \& Oliver 1977, Dayton et al. 1994). Deposit feeding is a relatively common and potentially important feeding strategy in these softbottom communities; it is employed by benthic foraminiferans, sea anemones, polychaetes and echinoderms (Dayton \& Oliver 1977, Oliver \& Slattery 1985, Bernhard 1987. McClintock 1994). On the west side of McMurdo Sound a substantial proportion of the available organic material is confined to soft sediments and within various micro-deposit feeders (Dayton et al 1986, Rivkin \& DeLaca 1990). The presence of an extensive soft sediment resource on the west side of McMurdo Sound, and rarely on the east side of 
McMurdo Sound, may partially explain the distribution pattern of $G$. antarctica

Gut content analyses of Gersemia antarctica colonies revealed a broad array of sediment sizes (particle sizes up to $500 \mu \mathrm{m}$ diameter). These were consistent with the average sediment size fractions in the vicinity of the soft corals $(63-125 \mu \mathrm{m}=20 \%$ dry wt; $125-300 \mu \mathrm{m} \geq$ $50 \%$ dry wt; $300-500 \mu \mathrm{m} \approx 13 \%$ dry wt; Bowser \& Bernhard 1993, S. Bowser unpubl. data). In addition to sediments, guts contained broken foraminiferan tests, benthic diatom frustrules, and unidentified particulate organic matter in proportions of $68,4,1$, and $27 \%$ by volume of the total sample $(n=15$ polyps per each of 4 colonies examined), respectively. Given the relatively small number of polyps examined we were unable to address the issue of feeding selectivity patterns. However, preliminary sediment core data $\left(44.2 \mathrm{~cm}^{2}\right.$ cores taken ca $0.3,0.6$, and $1.3 \mathrm{~m}$ from a G. antarctica colony. $\mathrm{n}=1$ each; J. Bernhard unpubl. data) suggest small soft species of foraminiferans such as Psammosphaera spp and Crithionina spp. may be impacted by soft coral deposit feeding. Lower numbers of these species were found within reach of the $G$. antarctica polyps $(0.3 \mathrm{~m}=$ 10 individuals) than outside the reach of the soft coral polyps ( 0.6 and $1.3 \mathrm{~m}=63$ and 47 individuals respectively). It is interesting to note that the patchy distribution of $G$. antarctica in Explorer's Cove appeared to exhibit a correlation with sediment sizes. Fewer large colonies were located in the central portion of Explorer's Cove, downstream from the Commonwealth Stream mouth $\left(0.8\right.$ colonies per $\left.100 \mathrm{~m}^{2}\right)$, than throughout the rest of the embayment ( 4 colonies per $100 \mathrm{~m}^{2}$ Slattery \& McClintock 1995). This region of Explorer's Cove was characterized by some of the largest grain sizes in western McMurdo Sound $(\phi=1$; D. Bockus unpubl. data) and the sediment would be difficult for soft coral polyps to manipulate as a food source. However, these patterns might also reflect other abiotic influences on distribution; for instance sediment scour may be more intense in that region of Explorer's Cove (M. Slattery \& D. Bockus unpubl. data). It is unclear whether $G$. antarctica is an obligate deposit feeder, and colonies may supplement deposit-derived diets with some planktonic organisms or suspended particulates. Clearly water flow characteristics at Explorer's Cove could not adequately cycle plankton within the system; time lapse video estimates of current in close proximity to $G$ antarctica indicate a tidal flow of considerably less than $1 \mathrm{~cm} \mathrm{~s}^{-1}$. Although there is likely not enough suspended material to maintain soft coral colonies indefinitely, sediment in Explorer's Cove is continually resuspended by the ventilation and escape behaviors of the scallop Adamussium colbecki (Mullineaux \& DeLaca 1984, Stockton 1984, Alexander \& Delaca 1987), various bioturbating echinoderms such as Abatus nimrodi (McClintock 1994, M. Slattery pers. obs.), and fish movement (Trematomus bernachii; $\mathrm{S}$. Bowser pers. obs.). It is also worth noting that a potential consequence of large size in colonial soft corals is reduced capture efficiency by individual polyps; thus $G$. antartica may have evolved a deposit feeding strategy for reasons related to colony size (Sebens 1982, McFadden 1986, Patterson 1991a).

Conditions on the western side of McMurdo Sound are unfavorable for many alcyonacean soft corals as these require significant light (if photoautotrophic; Fabricius \& Klumpp 1995), rapid currents (for passive suspension feeding and removal of sediment; Patterson 1991b, Riegl 1995), and little sedimentation (to avoid smothering or scouring; Riegl 1995, M. Slattery \& D. Bockus unpubl. data). Gersemia antarctica appears unique among alcyonacean soft corals in these characteristics. Little is known about the biology of deep-sea soft corals, including representative congeners. Nearshore benthic communities of Antarctica have been viewed as a 'deep-sea model' (Dayton et al. 1982, Pearse et al. 1991, Gooday et al. 1996); in support of this concept the Antarctic soft coral Alcyonium paessleri is a member of the shallow subtidal (15 to $30 \mathrm{~m}$ ) in McMurdo Sound but exhibits a deep-sea distribution $(\geq 450 \mathrm{~m}$ ) in lower latitudes (Williams 1986, Slattery \& McClintock 1995). Although the lower latitude distributions of $G$. antarctica are unknown, its Arctic congener $G$. rubiformis exhibits a similar trend (M. Slattery pers. obs). Deep-sea substrate is primarily comprised of soft sediment and feeding strategies are invariably coupled to the utilization of organic material associated with sediments (Gage \& Tyler 1991, Grebmeier \& Barry 1991). It is possible that $G$. antarctica has afforded us a glimpse of a unique feeding strategy that occurs among deep water colonial soft corals.

Acknowledgements. We thank the Antarctic Support Associates, the National Science Foundation, and the US Naval Antarctic Support Force at McMurdo Station for logistical support. The tireless effort in the field by $S$. Alexander, D Anderson, J. Bernhard, D. Bockus, P. Bryan, A. Gooday, M. Hamann, J. Heine, M. Hickey, J Mastro, N. Pollock, R. Sanders, and J. Weston is appreciated. S. Beddingfield provided the line drawings for which we are grateful. Comments by 3 anonymous reviewers improved this manuscript. This research was supported by NSF grants awarded to M.S. (OCE 9528570), J.B.M. (OPP 8815959, OPP 9118864 and OPP 9530735), and S.S.B. (OPP 9220146).

\section{LITERATURE CITED}

Alexander SP, DeLaca TE (1987) Feeding adaptations of the foraminiferan Cibicides refulgens living epizoically and parasitically on the antarctic scallop Adamussium colbecki. Biol Bull (Woods Hole) 173:136-159

Barry JP, Dayton PK (1988) Current patterns in McMurdo Sound, Antarctica and their relationship to local biotic communities. Polar Biol 8:367-376 
Bernhard JM (1987) Foraminiferal biotopes in Explorer's Cove, McMurdo Sound, Antarctica. J Foram Res 17:286-297

Bowser SS, Bernhard JM (1993) Structure, bioadhesive distribution and elastic properties of the agglutinated test of Astrammina rara (Protozoa: Foraminiferida). J Euk Microbiol 40:121-131

Dayton PK, Morcida BJ, Bacon F (1994) Polar marine communities. Am Zool 34:90-99

Dayton PK, Newman WA, Oliver J (1982) The vertical zonation of the deep-sea Antarctic acorn barnacle, Bathylasma corolliforme (Hoek): experimental transplants from the shelf into shallow water. J Biogeogr 9:95-109

Dayton PK, Oliver JS (1977) Antarctic soft-bottom benthos in oligotrophic and eutrophic environments. Science 197: $55-58$

Dayton PK, Watson D, Palmisano A, Barry JP, Oliver JS, Rivera D (1986) Distribution patterns of benthic microalgal standing stock at McMurdo Sound, Antarctica. Polar Biol 6:207-213

Fabricius KE, Benayahu Y, Genin A (1995) Herbivory in asymbiotic soft corals. Science 268:90-92

Fabricius KE, Klumpp DW (1995) Widespread mixotrophy in reef-inhabiting soft corals: the influence of depth, and colony expansion and contraction on photosynthesis. Mar Ecol Prog Ser 125:195-204

Gage JD, Tyler PA (1991) Deep sea biology: a natural history of organisms at the deep-sea floor. Cambridge University Press, New York

Gooday AJ, Bowser SS, Bernhard JM (1996) Benthic foraminiferal assemblages in Explorer's Cove, Antarctica: a shallow-water site with deep-sea characteristics. Prog Oceanogr 37:117-166

Grebmeier JM. Barry JP (1991) The influence of oceanographic processes on pelagic-benthic coupling in polar regions: a benthic perspective. J Mar Syst 2:495-518

LaBarbera M (1984) Feeding currents and particle capture mechanisms in suspension feeding animals. Am Zool 24 $71-84$

Lewis JB (1982) Feeding behaviour and feeding ecology of the Octocorallia (Coelenterata: Anthozoa). J Zool Lond $196: 371-384$

McClintock JB (1994) Trophic biology of antarctic shallowwater echinoderms. Mar Ecol Prog Ser 111:191-202

McFadden CS (1986) Colony fission increases particle capture rates of a soft coral: advantages of being a small colony. J Exp Mar Biol Ecol 103:1-20

Mullineaux LS, DeLaca TE (1984) Distribution of antarctic benthic foraminifers settling on the pecten Adamussium colbecki. Polar Biol 3:185-189

This note was presented by J. Pawlik, Wilmington, North Carolina, USA
Muscatine L, McCloskey LR, Marian RE (1981) Estimating the daily contribution of carbon from zooxanthellae to coral animal respiration. Limnol Oceanogr 26:601-611

Muscatine L, Porter JW (1977) Reef corals: mutualistic symbiosis adapted to nutrient poor environments. BioSci 27 . $454-460$

Oliver JS, Slattery PN (1985) Effects of crustacean predators on species composition and population structure of softbodied infauna from McMurdo Sound, Antarctsca. Ophelia $24: 155-175$

Patterson MR (1991a) Passive suspension feeding by an octocoral in plankton patches: empirical test of a mathematical model. Biol Bull (Woods Hole) 180:81-92

Patterson MR (1991b) The effects of flow on polyp-level prey capture in an octocoral. Alcyonium siderium. Biol Bull (Woods Hole) 180:93-102

Pearse JS, McClintock JB, Bosch I (1991) Reproduction of Antarctic benthic invertebrates: tempos, modes, and timing. Am Zool 31:65-80

Riegl R (1995) Effects of sand deposition on scleractinian and alcyonacean corals. Mar Biol 121:517-526

Rivkin RB, DeLaca TE (1990) Trophic dynamics in antarctic benthic communities: I. In situ ingestion of microalgae by Foraminifera and metazoan meiofauna. Mar Ecol Prog Ser 64:129-136

Sebens KP (1982) The limits to indeterminate growth: an optimal size model applied to passive suspension feeders. Ecology 63:209-222

Slattery M. McClintock JB (1995) Population structure and feeding deterrence in three shallow-water Antarctic soft corals. Mar Biol 122:461-470

Slattery M, McClintock JB (1997) An overview of population biology and chemical ecology of three species of Antarctic soft corals. In: Antarctic communities: Proc 6th Int SCAR Symposia, Venice, Italy. Cambridge University Press, $p$ 309-315

Sorokin YI (1991) Biomass, metabolic rates and feeding of some common reef zoantharians and octocorals. Aust J Mar Freshwat Res 42:729-741

Stockton WL (1984) The biology and ecology of the epifaunal scallop Adamussium colbecki on the west side of McMurdo Sound, Antarctica. Mar Biol 78:171-178

Veron JEN (1995) Corals in space and time: the biogeography and evolution of the Scleractinia. Cornell University Press, Ithaca, NY

Williams GC (1986) Morphology, systematics, and variability of the Southern African soft coral Alcyonium variable (J. Stuart Thomson, 1921) (Octocorallia, Alcyoniidae). Ann S Afr Mus 96:241-270

Manuscript first received: August 28, 1996

Revised version accepted: January 24, 1997 